\title{
ABORDAGENS EPISTEMOLÓGICAS NAS PESQUISAS EM ADMINISTRAÇÃO: UMA ANÁLISE NAS DISSERTAÇÕES DE UM PROGRAMA DE PÓS-GRADUAÇÃO NO NORDESTE BRASILEIRO
}

\author{
L. C. S. ROCHA'; G. E. F. ARAÚJO' ${ }^{2}$; R. O. MARQUES ${ }^{3}$ \\ ${ }^{1}$ Professor de Administração do Instituto Federal do Sul de Minas Gerais - Campus Machado; ${ }^{2}$ Administrador da \\ Empresa Brasileira de Correios e Telégrafos; ${ }^{3}$ Professor de Administração da Universidade Federal de Campina \\ Grande \\ Email: luiz.rocha@mch.ifsuldeminas.edu.br; ge_eliakim@hotmail.com; josirobs@ig.com.br
}

Artigo submetido em julho/2012 e aceito em agosto/2012

\section{RESUMO}

Tendo como base a importância da epistemologia na condução das pesquisas em qualquer área de estudo e seu conhecimento por parte dos pesquisadores, a presente pesquisa descreveu quais foram as abordagens epistemológicas mais presentes nas dissertações de um Programa de Pós-Graduação em Administração no nordeste brasileiro entre o período de 2005 a 2007. Através da construção de um instrumento de coleta de dados, baseado no enfoque proposto por Ivone (2005) e enriquecido pelos enfoques epistemológicos dos quais Demo (1981) faz menção, foi feita uma análise de conteúdo nas 49 dissertações apresentadas no período referido, especificamente da problemática, caracterizando, assim, a pesquisa como qualitativa documental. Constatou-se que o enfoque epistemológico mais presente nas dissertações é o positivista, presente nas abordagens empiristapositivista hipotético-dedutiva e empirista-positivista, concluindo, portanto, que a necessidade de constatação empírica é muito presente nas pesquisas realizadas, mostrando a forte influência positivista no Programa de Pós-Graduação analisado. Assim, percebe-se que a dificuldade de expurgar uma necessidade de constatação empírica de relação de causa e efeito é tamanha.

PALAVRAS-CHAVE: Abordagem epistemológica; pesquisa; problema de pesquisa.

\section{EPISTEMOLOGICAL APPROACH IN MANAGEMENT RESEARCHES: AN ANALYSIS IN DISSERTATIONS OF A POST-GRADUATION PROGRAM IN THE BRAZILIAN NORTHEAST}

\section{ABSTRACT}

Based in the importance of epistemology in conducting researches in every area of study and its knowing by the researchers, this research described what were the epistemological approaches more present in dissertations of a Management Post-Graduation Program in the Brazilian northeast in the period of 2005 to 2007. Through the construction of a collection data instrument, based in the focus proposed by Ivone (2005) and enriched by the Demo's (1981) epistemological focus, was done a content analysis in 49 dissertations produced in the period studied, specifically of problematic, characterizing, therefore, the research as a documental qualitative research. Was detected that the epistemological approach more present in dissertations is the positivist approach, present in empirical-positivist hypothetical-deductive and empirical-positivist approaches, concluding, hence, that the necessity of empirical verification is very present in the analyzed researches, showing the strong positivist influence in the analyzed Post-Graduation Program. Thus, is possible to perceive that is wide the difficulty to expel a necessity of a cause and effect empirical evidence.

KEY-WORDS: Epistemological approach; research; research problem. 


\section{ABORDAGENS EPISTEMOLÓGICAS NAS PESQUISAS EM ADMINISTRAÇÃO: UMA ANÁLISE NAS DISSERTAÇÕES DE UM PROGRAMA DE PÓS-GRADUAÇÃO NO NORDESTE BRASILEIRO}

\section{INTRODUÇÃO}

A preocupação com a qualidade das pesquisas científicas na área de administração não é um tema novo. $\mathrm{O}$ aumento das exigências e a candura quanto ao rigor metodológico, assim como uma maior intimidade com técnicas estatísticas, pretendem certificar uma perspectiva mais científica, tornando os trabalhos em ciências sociais mais agradáveis à academia.

Os paradigmas metodológicos próprios das ciências da natureza são explicados a partir da análise do seu próprio processo evolutivo. O estudo do homem como objeto científico é uma ideia surgida no século XIX, quando as ciências matemáticas e naturais já estavam constituídas (CHAUI, 2002). Para alcançar respeitabilidade científica, as ciências sociais passaram a estudar seu objeto empregando concepções metodológicas utilizadas naqueles campos do conhecimento (IUDÍCIBUS; THEÓPHILO, 2001).

Considerada por alguns como um ramo da ciência que não possui métodos e técnicas de investigação exclusiva, a administração utiliza-se de técnicas e metodologias de outras ciências (BUNGE, 1980). As pesquisas em administração têm o objetivo de conferir às suas descobertas uma pretensa objetividade e universalidade, porém, é diferente de outras áreas das ciências como matemática ou biologia, onde existe uma adequação do método com o objeto da pesquisa (MARTINS, 1994). Além disso, tem-se que a imagem de neutralidade científica é ilusória (CHAUI, 2002). Nem mesmo a extensão afiançada por um método científico poderia controlar a influência da subjetividade própria do ser humano, que se faz sempre evidente durante todo o processo de pesquisa, desde a eleição dos objetos, passando pelo estabelecimento das hipóteses, seleção e recorte do campo de estudo, até as análises e interpretações. A ideia de que as ciências sociais muitas vezes produzem resultados que são contestados, por não se aproximarem de um padrão de estabilidade e precisão próprio das ciências naturais tem perdido força desde a postulação do Princípio da Incerteza de Heisenberg e a constatação de que o observador também pode interferir nos fenômenos naturais (IUDíCIBUS; THEÓPHILO, 2001). Nesse contexto, Chaui (2002, p.281) ainda cita que, "quando o cientista escolhe certa definição de seu objeto, decide usar um determinado método e espera obter certos resultados, sua atividade não é neutra nem imparcial, mas feita por escolhas precisas".

Com relação às pesquisas em ciências sociais, os aspectos metodológicos, ainda são alvos frequentes de críticas, mostrando assim, a persistência, de dificuldades quanto à utilização dos instrumentos e dados analisados. Algumas críticas têm sido observadas nas pesquisas em ciências sociais, principalmente, quando se trata de estudos dos fenômenos de forma isolada, quando há uma ênfase demasiada nas análises quantitativas ou crenças (IUDíCIBUS; THEÓPHILO, 2001). 
A tentativa de se enquadrar aos métodos, técnicas e teorias naturais, e o fato de haver desigualdade e fragmentação nesse campo de estudo colaboram para que este seja um "campo historicamente contestado" (REED, 2007). Corroborando essa afirmação, Chaui (2002, p.271) cita que:

como, entretanto, não era possível realizar uma transposição integral e perfeita dos métodos, das técnicas e das teorias naturais para os estudos dos fatos humanos, as ciências humanas acabaram trabalhando por analogia com as ciências naturais e seus resultados tornaram-se muito contestáveis e pouco científicos.

A escolha do método científico pelo investigador pode revelar aspectos de sua visão de mundo, sua preocupação com o referencial teórico, a relação investigador versus realidade, enfim, a lógica da pesquisa empreendida (FILHO et al., 2006).

Isso demonstra que uma escolha errada da abordagem poderá comprometer todo o trabalho de pesquisa, por não atender aos objetivos propostos inicialmente. A escolha da abordagem estará diretamente relacionada com a linha filosófica utilizada pelo pesquisador para direcionar o seu trabalho, assinalando a tendência a ser seguida.

Com a finalidade de melhor conhecer a produção acadêmica de um Programa de PósGraduação em Administração do nordeste brasileiro em termos de enfoque epistemológico, a presente pesquisa buscou responder ao seguinte questionamento: quais foram as abordagens epistemológicas mais presentes nas dissertações produzidas entre o período de 2005 a 2007?

Além desta parte introdutória, o artigo apresenta o seguinte ordenamento: a segunda parte traz informações sobre a "Pesquisa em Administração", a terceira discorre sobre o "Problema de Pesquisa", a quarta apresenta as "Abordagens Epistemológicas", a quinta apresenta a "Metodologia" utilizada no presente trabalho, a sexta parte corresponde à "Análise dos Dados" e, por fim, tem-se as "Considerações Finais".

\section{PESQUISA EM ADMINISTRAÇÃO}

Uma preocupação se ressalta nas instituições brasileiras: promover a melhoria qualitativa da pesquisa feita no Brasil, visando ao alcance de níveis de qualidade que permitam a aceitação em eventos fora do país e a publicação em revistas acadêmicas internacionais de ponta. Um desafio que ainda persiste aos pesquisadores brasileiros é o reconhecimento pela comunidade acadêmica internacional da qualidade das produções acadêmicas brasileiras (VERGARA; CARVALHO JR., 1995).

Por outro lado, Kirshbaum, Porto e Ferreira (2004), declaram que o acadêmico em administração no Brasil está passando por uma encruzilhada: por um lado, já não pode mais legitimar sua posição apenas com a atividade docente, sendo obrigado a produzir conhecimento. 
Entretanto, sua pesquisa não atende aos critérios de excelência esperados. Nesse aspecto, é necessário destacar que o referencial para reconhecimento ainda tem sido estrangeiro, não sendo um fenômeno restrito ao Brasil. No Reino Unido, algumas pesquisas têm sido influenciadas pelos padrões e normas utilizados nos Estados Unidos. As citações de autores americanos ainda prevalecem nos estudos acadêmicos europeus em relação aos seus pares continentais, enquanto que as referências de estudos europeus nas publicações americanas são observadas com muito menor frequência (BERTERO; KEINERT, 1994).

Outro ponto a ser observado é a existência de certa dificuldade entre a ligação do mundo acadêmico com a prática profissional, proporcionando um aspecto crítico e paradoxal (BERTERO; CALDAS; WOOD JR., 1999). Como o aprendizado profissional da administração possui um aspecto prático, espera-se que a teorização venha a complementar e aprimorar a prática, sendo o contexto da "academia distanciada" um paradoxo a ser eliminado (BERTERO, 2006). Observa-se que, apesar do crescimento quantitativo e qualitativo da produção científica brasileira na área da administração, esta não tem sido aproveitada, como deveria, pelos profissionais da administração. Nesse contexto, observar-se certo desapontamento com relação ao caráter narcisista que alimenta a motivação de muitos pesquisadores (LEAVITT, 1996), insistindo em temas de pouca utilidade ao meio empresarial, se preocupando mais com a busca frenética de quantidades de produções em detrimento da qualidade (STARKEY; MADAN, 2001). Por outro lado, observa-se um hiato entre aquilo que é produzido e a realidade dos profissionais da área, visto que, a dificuldade ocorre por ocasião da forma como este material é apresentado ao público, em linguagem densa e com termos muito próprios dos acadêmicos (PRATA, 1998). Nesse sentido, as pesquisas desenvolvidas e seus resultados visam satisfazer aos próprios pesquisadores e seus pares (GARCIA; CARRIERI, 2001). Especificamente neste ponto, suscita-se a discussão entre as relações da teoria com a prática. Marsden e Townley (2001) argumentam que, mesmo tendo sido ultrapassada pelos desenvolvimentos na filosofia da ciência social, o entendimento de senso comum sobre teoria e prática é importante, pois, a maior parte dos leigos, e não poucos analistas organizacionais, subscreve a visão, na qual "a 'teoria' recorre ao mundo do pensamento e reflexão, enquanto a 'prática' recorre ao mundo da ação, do fazer coisas. Teoria e prática são interpretadas como diferentes" (MARSDEN; TOWNLEY, 2001, p.31). Os autores citam que a teoria é explicada de forma pejorativa, como inexequível, irreal ou "acadêmica", sendo a prática a antítese da teoria (MARSDEN; TOWNLEY, 2001). Porém, Marsden e Townley (2001) citam que essa visão filosoficamente ingênua foi há muito tempo destruída uma vez que passa-se a considerar a teoria e a prática como entes indissociáveis, e argumentam (MARSDEN; TOWNLEY, 2001, p.31): "a maioria das práticas operacionaliza alguma teoria, por mais implícita, vaga e contraditória que ela possa ser. De fato, 'prática' é um constructo teórico e a teorização é, em si mesma, uma prática".

Já Chaui (2002) cita que desde a Renascença, duas concepções sobre o valor da ciência sempre estiveram em confronto: o "ideal do conhecimento desinteressado" e o utilitarismo. A primeira delas afirma que "o valor de uma ciência encontra-se na qualidade, no rigor e na 
exatidão, na coerência e na verdade de uma teoria, independentemente de sua aplicação prática" (CHAUI, 2002, p.279), enquanto a segunda prega que "o valor de uma ciência encontrase na quantidade de aplicações práticas que possa permitir" (CHAUI, 2002, p.279). Apesar de ser tida como uma disciplina utilitarista (AKTOUF, 2001), a administração, pelo menos no contexto brasileiro, parece estar carente de aplicabilidade, quando se evidencia a relatada "distância" entre a academia e os profissionais (BERTERO, 2006).

A Escola Brasileira de Administração Pública e de Empresas da Fundação Getúlio Vargas tem sido uma das poucas exceções no sentido de reduzir esse paradoxo, disponibilizando, a uma quantidade maior de público, o resultado de suas pesquisas, numa linguagem mais acessível (BERTERO; KEINERT, 1994).

A pesquisa em administração possui problemas que parecem perenes, visto que, características problemáticas ainda persistem, proporcionando pesquisas de qualidade insatisfatória e quantidade insuficiente. Desta forma, é muito frequente que tais características se façam visíveis ao se participar de um curso de metodologia da pesquisa em administração, onde é assinalada a necessidade de proporcionar melhorias diante das dificuldades existentes nessa área em face da insatisfação que ocorre por parte dos docentes e alunos em função dos resultados obtidos nessa área (BERTERO, 1984).

Uma das características pertinentes é a questão da interdisciplinaridade que existe nesta área, envolvendo a utilização de conhecimentos diversificados de outras áreas em todo o processo da pesquisa, seja ela instrumental, e a efetiva realização da pesquisa. Nessa perspectiva, fica difícil observar em muitas pesquisas administrativas o conteúdo propriamente administrativo devido à existência de ecletismo chegando-se a duvidar se muitas das pesquisas que são tidas como da área de administração não pertencem a outras áreas do conhecimento (BERTERO, 1984).

Um dos motivos que poderia ser destacado para a existência dessa dificuldade obscuramente expressa foi mencionado por Bertero (1984) ao citar que esse comportamento refletia a pobreza analítica da área de pesquisa em administração, com pouca capacidade de identificar os problemas existentes. Desta forma, percebe-se a existência de certa limitação no exercício do pensar e do refletir filosoficamente, principalmente, quando está envolvida a interdisciplinaridade de que tanto se discorre (FAZENDA, 1999). Talvez por este motivo, alguns docentes-pesquisadores nessa área percebam certa alienação por parte de uma boa parcela de seus alunos, quanto à forma de refletir nas questões vivenciadas no dia-a-dia, principalmente quando se caracterizam neófitos buscando alcançar um espaço nesse meio acadêmico, cada vez mais exigente (BERTERO, 1984).

Como existe uma grande variedade de instrumentos para a realização de pesquisa em administração, observa-se, como consequência, uma maior complexidade disponível, proporcionando maior dificuldade para os pesquisadores dessa área. Tal fato é ressaltado através 
do descontentamento dos alunos que esperam uma maior praticidade na utilização dessas ferramentas, como também a complexidade encontrada na análise dos dados (MELLO; DUTRA; OLIVEIRA, 2000). Por outro lado, como essa dificuldade já foi percebida, providências serão necessárias no sentido de tentar reverter esse quadro, no menor tempo possível, proporcionando uma melhor expansão de quantidade e qualidade nas pesquisas realizadas nessa área (MELLO; DUTRA; OLIVEIRA, 2000).

Uma forma interessante que poderia ser utilizada nos cursos de metodologia científica, principalmente na área de administração, seria uma maior abordagem dos problemas epistemológicos e filosóficos da ciência. Bertero (1984) já destacava que o curso de metodologia não poderia ser voltado exclusivamente para os aspectos instrumentais, enfatizando com isso, a importância no desenvolvimento do pensar.

Como já mencionado, na pesquisa em administração, percebe-se um ecletismo oriundo de outras áreas, podendo acarretar questionamentos quanto à sua própria cientificidade (BERTERO, 2006). Isso ocorre, talvez, pelo fato de que algumas pesquisas, caracterizadas como de administração, dediquem maior esforço com temas mais pertinentes a outras áreas do conhecimento, tais como, sociologia, psicologia, serviço social, entre outras. Por outro lado, também podem existir pesquisas que, aparentemente, pareçam evadir dos temas administrativos, mas, podem proporcionar um maior esclarecimento de algumas problemáticas que desafiam a administração. O exemplo considerado clássico que poderia ser usado foi a pesquisa de Mayo na fábrica de Hawthorne da Western Electric, em Chicago, de 1927 à 1932. Esta pesquisa, que possuía características aparentemente associadas somente à psicologia, proporcionou importantes descobertas, trazendo benefícios consideráveis às teorias administrativas, com novas formas de pensar (BERTERO, 1984).

Moreira (2004) enfatiza a existência de convergência entre os temas das pesquisas acadêmicas e as chamadas pesquisas profissionais. Isso denota a preocupação com problemas que são similares a ambas as áreas, ficando um pouco sem sentido os esforços praticados de forma isolada.

\section{PROBLEMA DE PESQUISA}

Primeiramente, é importante, antes de discorrer sobre o "problema", defini-lo, e Cervo e Bervian (1983) fazem isso de uma forma bem simplificada quando colocam que "problema é uma questão que envolve intrinsecamente uma dificuldade teórica ou prática, para a qual se deve encontrar uma solução". Analisando a afirmação dos autores, pode-se perceber que o problema é o cerne da pesquisa, pois é nele que está o seu foco; é o que será necessário resolver para que uma teoria, por exemplo, possa ser refutada ou confirmada, dependendo da abordagem em que se embasa. De acordo com os mesmos autores, a investigação só se inicia quando o problema é formulado. 
A partir do "problema", o direcionamento das outras etapas será traçado. Segundo Quivy e Campenhoudt (2003), com base no "problema" formulam-se os principais pontos de referência teórica, os conceitos fundamentais e as ideias gerais que darão sustentação à análise. Conceber uma problemática é escolher uma orientação teórica, uma relação com o objeto de estudo. Segundo os autores, "[...] a pergunta de partida tornar-se-á verdadeiramente a pergunta central da investigação, na qual se resumirá o objetivo do trabalho" (QUIVY; CAMPENHOUDT, 2003, p.102).

É notória a importância da problemática para a consecução da pesquisa como se observa nas falas dos autores acima citados. A formulação do "problema" é até mesmo mais importante do que a própria resposta alcançada (CERVO; BERVIAN, 1983).

E sua importância se dá pela forma como ele é concebido. O "problema" não nasce do nada. Ele é formulado, decorrente de interesses do pesquisador ou de um grupo, ou mesmo "resultante da própria subcultura" (SCHRADER, 1978, p.18) de determinada ciência (CHAUI, 2002, TRIVIÑOS, 2007). Existem pré-concepções que existem e devem ser levadas em consideração quando da sua formulação. Schrader (1978) faz uma ressalva quando discute a exclusividade que um dos interesses pode causar no resultado da investigação. Para ele, toda exclusividade deve ser abolida, ou seja, é mais interessante quando dois ou mais interesses convergem. Porém, o mais importante é que quem irá realizar a pesquisa esteja realmente engajado no projeto, onde sem isso, estará passível, a pesquisa, de faltar-lhe criatividade.

Alguns requisitos são importantes na construção do problema. Segundo Triviños (2007, p. 96), “[...] qualquer que seja o ponto de vista teórico que oriente o trabalho do investigador, a precisão e a clareza são obrigações elementares [...]". Por exemplo, quando se busca trabalhar com o enfoque teórico positivista é importante que no problema esteja explícita a relação entre fenômenos (TRIVIÑOS, 2007). Ainda segundo o autor, a delimitação do "problema" é que vai especificar qual fundamentação teórica será utilizada na pesquisa.

Observa-se a riqueza que o problema pode explicitar em apenas um questionamento e é através dessa riqueza que o presente estudo torna-se possível, buscando relacionar quais os tipos de abordagens epistemológicas transparecem nos problemas de pesquisa.

\section{ABORDAGENS EPISTEMOLÓGICAS}

Vários são os métodos de pesquisa disponíveis e sua escolha depende do tipo de estudo a ser feito, dos resultados a serem perseguidos e do pesquisador que irá utilizá-los.

Theóphilo (2000 apud IVONE, 2005, p.36) organiza os elementos do processo de construção do objeto científico em 4 pólos: o pólo epistemológico, o teórico, o técnico e o metodológico. Para este estudo, apenas será analisado o pólo epistemológico. 
A palavra epistemologia é composta de dois termos gregos (episteme, que significa ciência, e logia, que significa conhecimento) e pode ser considerada como a ciência que estuda a ciência, ou seja, que estuda como o conhecimento é construído (CHAUI, 2002). É um ramo da filosofia que segundo Brabo (2007) estuda os princípios, as hipóteses das ciências, determinando sua origem lógica, seu valor e sua objetividade.

O pólo epistemológico é o que mais pode ser identificado no problema de pesquisa. Ivone (2005, p.36) diz que:

no pólo epistemológico, opera-se a permanente construção do objeto científico e a definição dos limites da problemática de investigação, ocorrendo uma constante reformulação dos parâmetros discursivos, dos paradigmas e dos critérios de cientificidade que orientam todo o processo de investigação.

A subdivisão do pólo epistemológico é concebida por diferentes classificações, segundo alguns autores. Para Gamboa (1987), os enfoques epistemológicos que permeiam a pesquisa em educação, e que podem ser estendidos à pesquisa em ciências humanas e sociais são: abordagens empírico-analíticas, fenomenológico-hermenêuticas e crítico-dialéticas.

No entanto, Martins (1994) classifica os enfoques epistemológicos em: empirista, positivista, sistêmica, funcionalista, fenomenológica, hermenêutica e crítico-dialética.

Para esse estudo será utilizado um arcabouço conceitual dos enfoques epistemológicos propostos por Ivone (2005) e enriquecido pelos enfoques epistemológicos dos quais Demo (1981) faz menção, sendo estes, portanto, a base para a construção do instrumento de coleta. São eles: teórico-empirista, empirista-positivista hipotético-dedutiva, empirista-positivista hipotético-indutiva, empirista-positivista, sistêmica, estruturalista, fenomenológicohermenêutica e crítico-dialética.

ABORDAGEM TEÓRICO-EMPIRISTA:

Segundo Theóphilo (2000 apud IVONE, 2005, p.39):

para o empirista, a ciência explica apenas a face observável da realidade, ou a superfície dos fenômenos, sendo que essa é considerada a única dimensão alcançada pelos sentidos assumindo um papel relevante, acreditando que as pessoas têm a mesma capacidade de observação e de perceber os fatos com o mesmo grau de evidência.

Neste enfoque, a preocupação excessiva em explicar os fatos pela constatação na observação da realidade é a principal característica.

ABORDAGEM EMPIRISTA-POSITIVISTA HIPOTÉTICO-DEDUTIVA:

Apesar de ser tida como uma abordagem empirista, ela busca explicar uma teoria através da refutação desta, quando da observação na realidade. Demo (1981, p.114) cita que, segundo Popper (1965), "a experiência aparece como método de teste das teorias e não mais como critério de demarcação cientifica". Nesse enfoque o critério de verificabilidade é substituído pelo critério de falsificabilidade. 
A ideia de Popper (1965 apud DEMO, 1981, p.122) era de que a teoria fosse aceita não tentando comprová-la positivamente, mas sim, testando se suas hipóteses eram fortes o bastante, com o objetivo de encontrar lacunas para a sua verificação como teoria. Segundo esse enfoque, qualquer teoria pode ser derrubada quando uma de suas conclusões for falsa. Por isso, este é chamado de fasificabilidade radical.

\section{ABORDAGEM EMPIRISTA-POSITIVISTA HIPOTÉTICO-INDUTIVA:}

Segundo o Empirismo Indutivo, "a generalização é produto da observação repetida, nunca anterior a esta" (DEMO, 1981, p.105). "Para se estabelecer uma regularidade cientifica é necessário, antes de tudo, contar empiricamente a repetição suficiente de casos concretos confirmadores da suposta regularidade" (DEMO, 1981, p.106). O ponto de partida do pensamento é a observação verificável. A teoria, nessa abordagem, é construída aos poucos através dos vários estudos que vêm a comprová-la. Diferentemente da hipotético-dedutiva, essa abordagem busca a comprovação da teoria e não sua refutação (DEMO, 1981).

\section{ABORDAGEM EMPIRISTA-POSITIVISTA:}

Segundo Triviños (2007, p.34), um dos princípios básicos dessa abordagem é "[...] a busca da explicação dos fenômenos através das relações dos mesmos e a exaltação da observação dos fatos [...]". Esta abordagem toma a postura de não se interessar com os fatores determinantes dos fenômenos, mas sim, como se processam as relações entre os fatos. Essa busca pelas causas dos fenômenos era considerada para os positivistas como metafísico, por isso, impossível considerá-la ciência (TRIVIÑOS, 2007). Diante disto, a busca pelo "porquê" das coisas cai em detrimento de solucionar "como" as coisas acontecem.

As principais características do positivismo, segundo Demo (1981), são:

a) Regra do fenomenalismo: "o positivista não aceita a distinção entre o fenômeno e a essência" (DEMO, 1981, p.125). Para os positivistas, um fenômeno pode ser desvendado pela observação superficial do acontecimento. A essência, para os positivistas, é muito subjetiva para ser verificada empiricamente. Por isso, o que contava era o que se observava e não o que estava por trás. A essa característica pode-se aludir, também, a rejeição ao metafísico.

b) Regra do nominalismo: onde os "conceitos são tomados apenas como nomes a objetos concretos" (DEMO, 1981, p.125). A conceituação é uma forma abstrata não aceita pelos positivistas, pois não pode ser observável, por isso, a nominalização deles.

c) Regra da neutralidade científica: a qual perpassa a ideia de que "a experiência não experimenta valor, pois este não é constatado" (DEMO, 1981, p.126). Durkheim (1975), citado em Triviños (2007, p.34), diz que o papel dos cientistas é exprimir a realidade e não julgá-la como certa ou errada.

Crença na unidade do método científico: segundo os positivistas "[...] toda e qualquer realidade deve ser tratada cientificamente de forma semelhante, para não dizer idêntica" (DEMO, 1981, p.127). Já que o ideal para os positivistas era buscar a realidade dos fatos pelas suas relações, e só isso poderia explicar a verdade, todas as ciências deveriam guiar-se apenas por uma unidade metodológica.

ABORDAGEM ESTRUTURALISTA: 
Diferentemente do positivismo, o estruturalismo aceita que o conhecimento da explicação analítica de um objeto só se dá pela sua decomposição e não como pensam os positivistas pela superfície observável imediatamente (DEMO, 1981).

O estruturalismo recebe várias conotações, mas a que será utilizada nesse estudo é a de Levi-Strauss, na qual uma das características mais profundas, "em termos metodológicos, [...] é a acentuação firme de que o conhecimento da realidade se realiza plenamente apenas quanto atinge nela elementos constituintes em nível de constantes supratemporais e supra-espaciais" (DEMO, 1981, p.202). Esta foi a forma com que o estruturalismo pôde explicar como existiria um enunciado infinito (geral), sem recorrer à soma dos casos particulares, como preconizava os indutivistas.

Demo (1981, p.203) faz uma análise de uma passagem da obra mithologique, de LeviStrauss, da qual extrai os elementos mais centrais da perspectiva original do estruturalismo:

a) Privilegia-se o esforço de decomposição analítica. Ao final dele, pode-se encontrar, diante do objeto desmontado em suas partes, o cerne da questão.

b) Supera-se o problema da complexidade da realidade: o complexo existe apenas aparentemente, pois, na profundeza de sua decomposição analítica, descobre-se que a variação complexa se liga a um tema único.

c) Decide-se pela heurística da subjacência; o fenomenal é sempre variável e por isso não explicativo; é preciso desvendar o objeto dentro de uma técnica que coloque à luz seus elementos internos profundos.

d) A subjacência é estruturada em modelos construíveis, ou seja, para além do superficial emerge a ordem, a constância explicativa do fenômeno. Analiticamente reduzido, ele revela uma ordem interna invariante e que por isso o explica na sua compleição e na sua variação.

Uma diferença que se pode perceber com o enfoque crítico-dialético é que, no estruturalismo, a explicação é decorrente de uma análise da essência, desconsiderando a influência da história nesse campo. A história não é o único modo de explicar as coisas, sendo relegada a segundo plano. Porém, o seu valor ainda é considerado para emergir a explicação analítica dos fatos (DEMO, 1981).

Como o estruturalismo privilegia o aspecto relacional, já se poderia sustentar o seu intento formalizante (DEMO, 1981). "Não se estudam primordialmente os conteúdos, mas as relações entre eles, a que daríamos o nome de forma", porém, sem desconsiderar a permutabilidade do conteúdo (DEMO, 1981, p.223). "A formalização seria o caminho da objetividade e da exatidão" (DEMO, 1981, p.224). É nesse aspecto que o estruturalismo se aproxima das ciências exatas.

\section{ABORDAGEM SISTÊMICA:}

A diferença com o estruturalismo está no privilégio que dá à análise do todo, da síntese. Ou seja, diferentemente do estruturalismo, que explica o fenômeno pela sua decomposição 
buscando uma forma invariável, essencial que o explique, o sistemismo acredita que o fenômeno só pode ser explicado se o todo for considerado, porque ele só existe se o todo existir. As partes isoladas não são nada, “[...] nada resta” (DEMO, 1981, p.231). E essa crença está no fato de que o todo repassa mais um componente, que apenas com a soma das partes não é possível, a organização (BUCKLEY, 1971 apud DEMO, 1981, p.206).

Outro ponto importante desse enfoque é a cibernética. Esta introduziu no sistemismo a noção de realimentação, a qual pressupõe que o sistema é uma propriedade de toda organização, física ou humana (DEMO, 1981). Isso pode implicar em uma noção contrária, por exemplo, ao enfoque crítico-dialético, pois, não consideraria a superação de um determinado sistema pelo fato da existência dessa realimentação.

Diferentemente da abordagem crítico-dialética, esse enfoque não considera a superação do fenômeno, mas apenas a adaptação deste ao meio, mesmo aceitando que possam existir disfunções, desde que não afetem a organização. Essa é uma de suas principais características, a circularidade sistêmica (DEMO, 1981).

\section{ABORDAGEM FENOMENOLÓGICA-HERMENÊUTICA:}

Essa abordagem busca explicar os fenômenos como eles realmente são. Segundo Ivone $(2005$, p.40):

\footnotetext{
O interesse da fenomenologia não é o mundo que existe, mas o modo como o conhecimento do mundo se torna possível e se realiza. A fenomenologia analisa os fenômenos objetos da pesquisa, no sentido de compreendê-los, ou seja, tem por objetivo captar, desvendar e conhecer o significado desses fenômenos. Trata-se de descrever os fenômenos e não de analisar nem explicar.
}

Segundo Triviños (2007, p.47), essa abordagem "exalta a interpretação do mundo que surge intencionalmente à nossa consciência". Essa intencionalidade se configura como "a consciência de estar orientada para um objeto" (TRIVIÑOS, 2007, p.45). Diferentemente do positivismo, que toma o conhecimento construído num mundo objetivo, a fenomenologia considera que este é constituído de forma subjetiva.

Utilizam-se, nessa abordagem, métodos de pesquisa que privilegiam "a compreensão e a inteligibilidade como propriedades específicas para explicação e descrição dos fenômenos sociais" (IVONE, 2005, p.72).

\section{ABORDAGEM CRÍTICO-DIALÉTICA:}

Segundo Gamboa (1987, p.97) essa abordagem "questiona fundamentalmente a visão estática da realidade implícita nas abordagens anteriores". Demo (1981) resume os pressupostos teóricos que identificam a prática dessa abordagem, iniciando pela historicidade, caracterizada pela mobilidade constante da História, "o vir-a-ser contínuo das formações sociais" (DEMO, 1981, p.145). Marcuse, encontrado em Demo (1981, p.145), argumenta que "a condição básica para se empregar o predicado dialético é a propriedade de ser "histórico'", exemplo disso é a evolução dos tipos de sociedades. 
Outro pressuposto é o processo, significando que está sempre em formação, isto é, "de nunca ser algo completamente formado, acabado, fechado." (DEMO, 1981, p.146). Esta ideia de processo não necessariamente significa progresso, pode também denotar regresso. Pelo processo há uma busca incessante pelo estágio final que nunca virá. Esse fim que nunca chega é notável, porque, a dialética não concebe a noção de coisa fechada, acabada.

Demo (1981) cita, também, como pressuposto dessa abordagem, a mutação social, já bem conhecida, até pelos não dialéticos. Esse pressuposto preconiza que a mutação de uma sociedade ou de um sistema acontecerá sempre, mesmo que não o mude por completo, como queiram os funcionalistas (DEMO, 1981).

O próximo pressuposto citado pelo autor é a transcendência, que é mais uma continuidade da ação que se dá em um sistema anterior, pois defende a possibilidade, não apenas de um sistema rearranjar-se, mas também de superar-se radicalmente. Ou seja, existirão situações em que a crítica a determinado sistema seja tão necessária e sua mudança inevitável que a transcendência de um sistema para outro deve seguir-se.

Ainda segundo o autor, o conflito social, tido como um elemento comum dentro de qualquer sistema, podendo ser considerado como um elemento desestruturante, é "[...] capaz de levar à superação histórica" (DEMO, 1981, p.151). A mudança decorrente do conflito não pode ser concebida como de forma consensual, regulável. Os conflitos, como são também advindos internamente das formações sociais, são um dos condicionantes para a mudança junto com fatores externos (DEMO, 1981).

E por último, Demo (1981) cita a relatividade social, a qual parte do pressuposto de que "[...] a realidade social é relativa", querendo com isso dizer que "carrega dentro de si o sentido da provisoriedade, das fases subsequentes, da imperfeição, do constante vir-a-ser" (DEMO, 1981, p.152).

O Quadro 1 apresenta um resumo das características das abordagens epistemológicas citadas.

Quadro 1: Abordagens epistemológicas usadas no estudo e suas principais características

\begin{tabular}{|c|l|}
\hline $\begin{array}{c}\text { ABORDAGENS } \\
\text { EPISTEMOLÓGICAS }\end{array}$ & \multicolumn{1}{|c|}{ CARACTERÍSTICAS } \\
\hline TEÓRICO-EMPÍRICA & $\begin{array}{l}\text { Busca realizar o estudo tendo como base a teoria para } \\
\text { explicar os fatos; são estudos teóricos realizados em } \\
\text { textos ou documentos com caráter descritivo. }\end{array}$ \\
\hline EMPIRISTA-POSITIVISTA & $\begin{array}{l}\text { Preocupação com a explicação dos fatos através das } \\
\text { relações entre os fenômenos da realidade, } \\
\text { sincronicamente; utiliza observação experimentos do do } \\
\text { que é explícito, buscando uma refutação da teoria ou } \\
\text { hipótese; parte do geral ao específico, ou seja, da teoria } \\
\text { à prática, acreditando que pode existir neutralidade na } \\
\text { experiência. }\end{array}$ \\
\hline
\end{tabular}




\begin{tabular}{|c|c|}
\hline $\begin{array}{l}\text { EMPIRISTA-POSITIVISTA } \\
\text { HIPOTÉTICO-INDUTIVA }\end{array}$ & $\begin{array}{l}\text { Preocupação com a explicação dos fatos através das } \\
\text { relações entre os fenômenos da realidade, } \\
\text { sincronicamente; utiliza a observação e experimentos de } \\
\text { fatos em que se busca uma comprovação da teoria ou } \\
\text { hipótese; parte do especifico ao geral, ou seja, da prática } \\
\text { à teoria, acreditando que pode existir neutralidade na } \\
\text { experiência. }\end{array}$ \\
\hline EMPIRISTA-POSITIVISTA & $\begin{array}{l}\text { Consiste em estudar os fatos através das relações entre } \\
\text { eles, descrevendo e explicando os fenômenos; } \\
\text { caracterizam-se pelo experimento, controle e } \\
\text { sistematização de dados empíricos mediante análises } \\
\text { estatísticas. }\end{array}$ \\
\hline SISTÊMICA & $\begin{array}{l}\text { Estudos de caráter sistemático quanto ao enfoque lógico } \\
\text { de um sistema; têm como características explicar como o } \\
\text { objeto de estudo funciona, se institucionaliza e } \\
\text { sobrevive; utilizam teste dos instrumentos de coleta, } \\
\text { sistematização com análise de dados, organização e } \\
\text { controle das variáveis; a análise é feita tendo como } \\
\text { preocupação o todo. }\end{array}$ \\
\hline ESTRUTURALISTA & $\begin{array}{l}\text { Busca explicar o objeto de estudo através da } \\
\text { decomposição de sua estrutura, para atingir as } \\
\text { invariantes. }\end{array}$ \\
\hline $\begin{array}{l}\text { FENOMENOLÓGICO- } \\
\text { HERMENÊUTICA }\end{array}$ & $\begin{array}{l}\text { Preocupa-se em descrever os fenômenos como eles } \\
\text { realmente acontecem; busca a essência e não considera } \\
\text { a superficialidade do explícito. }\end{array}$ \\
\hline CRÍTICO-DIALÉTICA & $\begin{array}{l}\text { Considera a mudança, não apenas dentro do sistema, } \\
\text { mas do sistema como um todo, sempre presente; há } \\
\text { uma preocupação histórica para explicar os fatos. }\end{array}$ \\
\hline
\end{tabular}

Fonte: adaptado de Demo (1981) e Ivone (2005).

\section{METODOLOGIA}

Segundo Oliveira (2003 apud IVONE, 2005, p.60):

a abordagem qualitativa facilita descrever a complexidade de problemas e hipóteses, bem como analisar a interação entre variáveis, compreender e classificar determinados processos sociais, oferecer contribuições no processo das mudanças, criação ou formação de opiniões de determinados grupos e interpretação das particularidades dos comportamentos ou atitudes dos indivíduos.

Sendo assim, por possuir o objetivo de descrever qual a abordagem epistemológica das dissertações de um Programa de Pós-Graduação em Administração no período de 2005 a 2007, o presente estudo se classifica como um estudo qualitativo.

Quanto aos objetivos, enquadra-se como um estudo descritivo, visto que tem como objetivo principal apenas descrever em que medida estão sendo produzidas as dissertações no referido Programa de Pós-Graduação com relação às abordagens epistemológicas, indo no mesmo direcionamento do que profere Gil (1987, p.45) sobre a pesquisa descritiva, afirmando que a mesma tem "[...] como objetivo primordial a descrição das características de determinada 
população ou fenômeno ou estabelecimento de relações entre variáveis". A pesquisa, quanto à obtenção dos dados, se classifica como documental, pois, foram utilizados documentos (as dissertações). A natureza desta pesquisa exigiu atividades exploratórias de levantamento, sistematização e análise das características das dissertações de mestrado defendidas entre o período de 2005 a 2007.

Por ser uma pesquisa qualitativa e pelo objetivo que se pretende alcançar, a técnica de análise utilizada foi a análise de conteúdo. Richardson (1999) diz que o uso da análise de conteúdo, particularmente, se dá no estudo de material de tipo qualitativo. Segundo Quivy e Campenhoudt (2003, p.227), existem duas variações da análise de conteúdo, das quais, para esse estudo, será utilizado o método qualitativo, que "teria como informação de base a presença ou ausência de uma característica ou o modo segundo o qual os elementos do discurso estão articulados uns com os outros". Essa técnica consegue retirar do objeto pesquisado um pouco da sua essência. Ainda, de acordo com os autores, essa é justamente uma de suas vantagens. A análise de conteúdo no presente trabalho procedeu-se a partir da verificação de elementos característicos das abordagens epistemológicas nas problemáticas das dissertações.

De acordo com Triviños (2007), existem três etapas que conformam a técnica de análise de conteúdo. A primeira delas é a pré-análise que se exaure com a organização do material que será analisado. Na referida pesquisa, essa fase foi caracterizada pelo exame, de forma geral, nas dissertações para a seleção do objeto de análise.

$\mathrm{Na}$ segunda fase, descrição analítica, foi realizada a codificação, classificação e categorização das características epistemológicas retiradas da problemática das dissertações.

E a terceira etapa foi a interpretação inferencial, na qual o trabalho de reflexão e intuição do pesquisador é indispensável para que o conteúdo que está implícito possa vir à tona (TRIVIÑOS, 2007).

Mapearam-se 49 dissertações correspondentes ao total de defesas, entre o período de 2005 e 2007, destacando-se o período, o título, o autor, o orientador e a problemática, identificada como a parte onde estão inseridos a delimitação do estudo e a pergunta de partida das dissertações.

\section{ANÁLISE DOS DADOS}

Através da análise qualitativa dos conteúdos, foram sistematizados os dados referentes às dissertações que apontam à construção metodológica de uma pesquisa científica e são classificados nos padrões das características de cada abordagem epistemológica, a saber: empirista-positivista hipotético-dedutiva, empirista-positivista hipotético-indutiva, empiristapositivista, teórico-empirista, sistêmica, estruturalista, fenomenológico-hermenêutica e críticodialética. O título de cada dissertação e sua respectiva classificação estão apresentados no Quadro 2. 


\section{Quadro 2: Classificação epistemológica das dissertações de 2005 a 2007}

\begin{tabular}{|c|c|c|c|}
\hline № & ANO & TíTULO & $\begin{array}{c}\text { ABORDAGEM } \\
\text { EPISTEMOLÓGICA }\end{array}$ \\
\hline 1 & \multirow{11}{*}{2005} & $\begin{array}{l}\text { As finanças públicas sob a perspectiva da lei de responsabilidade fiscal: o } \\
\text { caso do município de Caicó }\end{array}$ & Teórico-empirista \\
\hline 2 & & $\begin{array}{l}\text { Avaliação de práticas de inteligência empresarial: um estudo de caso em } \\
\text { empresa do setor varejista do RN }\end{array}$ & Empirista-positivista \\
\hline 3 & & $\begin{array}{l}\text { Estratégico da Tecnologia da Informação em Busca da Competitividade: } \\
\text { Estudo de Casos Uso em Empresas do Rio Grande do Norte }\end{array}$ & $\begin{array}{l}\text { Empirista-positivista } \\
\text { hipotético-dedutiva }\end{array}$ \\
\hline 4 & & $\begin{array}{l}\text { Comprometimento e ética profissional: Um estudo de suas relações junto } \\
\text { aos contabilistas da cidade de Natal/RN }\end{array}$ & Empirista-positivista \\
\hline 5 & & $\begin{array}{l}\text { Aplicação do Método Scorecard Dinâmico no Processo de Formulação da } \\
\text { Estratégia de uma Empresa de Pequeno Porte }\end{array}$ & $\begin{array}{l}\text { Empirista-positivista } \\
\text { hipotético-dedutiva }\end{array}$ \\
\hline 6 & & $\begin{array}{l}\text { Alimentar a Fome ou Matar a Cidadania? Uma análise do programa de } \\
\text { distribuição de alimentos (PRODEA) no município de Canguaretama/RN }\end{array}$ & Empirista-positivista \\
\hline 7 & & $\begin{array}{l}\text { O Processo Redistributivo do Orçamento Participativo e do Congresso da } \\
\text { Cidade em Belém do Pará }\end{array}$ & $\begin{array}{l}\text { Empirista-positivista } \\
\text { hipotético-dedutiva }\end{array}$ \\
\hline 8 & & $\begin{array}{l}\text { Motivação e Satisfação à Luz do Modelo ASH: Estudo de Caso em Uma } \\
\text { Indústria de alimentos }\end{array}$ & $\begin{array}{l}\text { Empirista-positivista } \\
\text { hipotético-dedutiva }\end{array}$ \\
\hline 9 & & $\begin{array}{l}\text { Desenho do Trabalho e Comprometimento Organizacional: um estudo em } \\
\text { voluntários da cidade de Natal/RN }\end{array}$ & Empirista-positivista \\
\hline 10 & & $\begin{array}{l}\text { Otimização de Recursos de Marketing no Desempenho de Empresa } \\
\text { Holeteira: um estudo no Nordeste Brasileiro }\end{array}$ & $\begin{array}{l}\text { Empirista-positivista } \\
\text { hipotético-dedutiva }\end{array}$ \\
\hline 11 & & $\begin{array}{l}\text { A Ouvidoria e a Melhoria dos Serviços Públicos: uma experiência da } \\
\text { administração pública estadual do Rio Grande do Norte }\end{array}$ & $\begin{array}{l}\text { Empirista-positivista } \\
\text { hipotético-dedutiva }\end{array}$ \\
\hline 12 & & $\begin{array}{l}\text { O Processo de Implantação de Um Sistema Integrado de Gestão em Uma } \\
\text { Organização Pública à Luz da Teoria da Hospitalidade: um estudo de caso }\end{array}$ & $\begin{array}{l}\text { Empirista-positivista } \\
\text { hipotético-dedutiva }\end{array}$ \\
\hline 13 & & $\begin{array}{l}\text { A Satisfação dos Clientes Internos e o Comprometimento Organizacional: } \\
\text { um estudo à luz do modelo ASH nas indústrias alimentícias do RN }\end{array}$ & Empirista-positivista \\
\hline 14 & & $\begin{array}{l}\text { Atuação e Desempenho do Ministério Público do Estado do Rio Grande do } \\
\text { Norte no Contexto da Gestão Pública: perspectiva estratégica }\end{array}$ & Sistêmica \\
\hline 15 & & $\begin{array}{l}\text { Dinâmica da hospitalidade comercial: um estudo do caráter hospitaleiro em } \\
\text { empreendimento de lazer no Rio Grande do Norte }\end{array}$ & Empirista-positivista \\
\hline 16 & & $\begin{array}{l}\text { Comportamento do consumidor: um estudo do mercado imobiliário em } \\
\text { condomínios verticais fechados na região metropolitana de Natal }\end{array}$ & Empirista-positivista \\
\hline 17 & & $\begin{array}{l}\text { Gestão de Recursos Hídricos e Capital Social: o caso dos comitês de } \\
\text { gerenciamento da Bacia Hidrográfica do Rio Grande do Sul }\end{array}$ & Empirista-positivista \\
\hline 18 & 2006 & $\begin{array}{l}\text { Relações Entre Mecanismos de Coordenação e Controle com Desempenho } \\
\text { Organizacional: um estudo multi-caso nas instituições públicas de ensino } \\
\text { médio de Natal }\end{array}$ & Empirista-positivista \\
\hline 19 & & A Liderança e Suas Relações com o Comprometimento Organizacional & Empirista-positivista \\
\hline 20 & & $\begin{array}{l}\text { Educação Superior em Turismo: o profissional de turismo frente às } \\
\text { competências exigidas pelo mercado de trabalho do setor hoteleiro em } \\
\text { Natal }\end{array}$ & Empirista-positivista \\
\hline 21 & & $\begin{array}{l}\text { A Tecnologia da Informação como Fator de Competitividade em Um APL: o } \\
\text { caso do APL da carcinicultura do RN }\end{array}$ & Empirista-positivista \\
\hline 22 & & A Comunicação Interna Numa Organização Pública & Sistêmica \\
\hline 23 & & $\begin{array}{l}\text { Qualidade dos Empregos e a Carcinicultura Marinha nos Laboratórios da } \\
\text { Praia de Barreta/RN }\end{array}$ & $\begin{array}{l}\text { Empirista-positivista } \\
\text { hipotético-dedutiva }\end{array}$ \\
\hline 24 & & $\begin{array}{l}\text { Atenção Básica à Saúde da Criança: o caso do programa de saúde da família } \\
\text { (PSF) na unidade mista de Felipe Camarão - Distrito Oeste de Natal/RN - }\end{array}$ & Empirista-positivista \\
\hline
\end{tabular}




\begin{tabular}{|c|c|c|c|}
\hline & & $2000-2004$ & \\
\hline 25 & & O Marketing e a Atuação Social das Empresas: uma relação possível? & Empirista-positivista \\
\hline 26 & & $\begin{array}{l}\text { Implementação de Sofware Livre na Administração Pública: um estudo de } \\
\text { múltiplos casos no Estado do Rio Grande do Norte }\end{array}$ & Empirista-positivista \\
\hline 27 & & $\begin{array}{l}\text { Estrutura de Organizações Sociais: adaptação aos projetos sociais ou às } \\
\text { pressões institucionais? }\end{array}$ & Empirista-positivista \\
\hline 28 & & $\begin{array}{l}\text { Comunicação e Imagem Organizacional: um estudo de suas relações no } \\
\text { comércio varejista de shopping centers }\end{array}$ & Empirista-positivista \\
\hline 29 & & $\begin{array}{l}\text { Comércio Eletrônico no Mercado Potiguar: estágio de utilização pelas } \\
\text { maiores empresas do Rio Grande do Norte }\end{array}$ & Sistêmica \\
\hline 30 & & $\begin{array}{l}\text { Gestão do Marketing de Relacionamento: um estudo em empresas } \\
\text { hoteleiras de Natal/RN }\end{array}$ & Estruturalista \\
\hline 31 & & $\begin{array}{l}\text { Estratégias Competitivas Genéricas nas Empresas Comerciais Varejistas de } \\
\text { Shopping Centers: um estudo a partir do modelo de Porter }\end{array}$ & Sistêmica \\
\hline 32 & & $\begin{array}{l}\text { A expatriação de executivos: um estudo da adaptação de executivos } \\
\text { brasileiros na Argentina }\end{array}$ & Empirista-positivista \\
\hline 33 & & A Percepção da Qualidade, na Ótica de Alunos de Uma IES Privada e do MEC & Empirista-positivista \\
\hline 34 & \multirow{16}{*}{2007} & $\begin{array}{l}\text { Saúde bucal no programa de saúde da família: o caso do distrito sanitário } \\
\text { norte em Natal-RN }\end{array}$ & Empirista-positivista \\
\hline 35 & & $\begin{array}{l}\text { Qualidade de vida no trabalho na EMATER-RN: validação de um instrumento } \\
\text { síntese de pesquisa e diagnóstico }\end{array}$ & $\begin{array}{l}\text { Empirista-positivista } \\
\text { hipotético-dedutiva }\end{array}$ \\
\hline 36 & & $\begin{array}{l}\text { Comprometimento Organizacional e Esforço Instrucional de Docentes em } \\
\text { Instituições de Ensino Superior }\end{array}$ & Empirista-positivista \\
\hline 37 & & $\begin{array}{l}\text { Empreendedorismo e cultura: um estudo sobre empreendedores e } \\
\text { estrangeiros do RN }\end{array}$ & Empirista-positivista \\
\hline 38 & & $\begin{array}{l}\text { Compra por Impulso em Shopping Centers: Estudo do Comportamento e do } \\
\text { Perfil do Consumidor em Natal (RN) e Brasília (DF) }\end{array}$ & Estruturalista \\
\hline 39 & & $\begin{array}{l}\text { Controle Social de Políticas Públicas: O Conselho Turístico Pólo Costa das } \\
\text { Dunas }\end{array}$ & Estruturalista \\
\hline 40 & & $\begin{array}{l}\text { Impactos de Adoção de Sistemas de Informação no Judiciário: Pesquisa com } \\
\text { Usuários do Sistema Processual Virtual em um Juizado Especial Federal }\end{array}$ & Empirista-positivista \\
\hline 41 & & $\begin{array}{l}\text { Burnout: Analisando a Síndrome no Ramo das Indústrias Alimentícias do Rio } \\
\text { Grande do Norte }\end{array}$ & Empirista-positivista \\
\hline 42 & & $\begin{array}{l}\text { Do tratamento das reclamações à gestão da insatisfação: o comportamento } \\
\text { de empresas hoteleiras mediante a insatisfação de seus clientes }\end{array}$ & Empirista-positivista \\
\hline 43 & & $\begin{array}{l}\text { Fatores de Longevidade do Programa Central do Cidadão no Rio Grande do } \\
\text { Norte }\end{array}$ & Empirista-positivista \\
\hline 44 & & $\begin{array}{l}\text { Política de Exportação: Um Olhar Sobre a Evolução da Cultura de Melão do } \\
\text { Rio Grande do Norte }\end{array}$ & Empirista-positivista \\
\hline 45 & & $\begin{array}{l}\text { A Representação Social do Papel de Gestores em Organizações Não- } \\
\text { Governamentais }\end{array}$ & $\begin{array}{l}\text { Empirista-positivista } \\
\text { hipotético-dedutiva }\end{array}$ \\
\hline 46 & & $\begin{array}{l}\text { Mapeando Fundamentos do Construto Neuromarketing com Profissionais } \\
\text { de Empresas de Publicidade }\end{array}$ & Empirista-positivista \\
\hline 47 & & $\begin{array}{l}\text { Do Talão de Nota Fiscal ao Cupom Fiscal: a Implantação do ECP no Estado do } \\
\text { Rio Grande do Norte e sua Repercussão na Arrecadação do ICMS }\end{array}$ & Empirista-positivista \\
\hline 48 & & $\begin{array}{l}\text { Cultura Organizacional e Qualidade dos Serviços Turísticos: Um Estudo no } \\
\text { Setor de Restaurantes }\end{array}$ & Empirista-positivista \\
\hline 49 & & $\begin{array}{l}\text { A Formação e o desenvolvimento de Arranjos Cooperativos sob a Ótica da } \\
\text { Imersão Social e da Economia dos Custos de Transação: Um Estudo de Caso } \\
\text { na Coopercam e na Unipesca }\end{array}$ & Empirista-positivista \\
\hline
\end{tabular}


Identificou-se, através das 49 dissertações analisadas no período de 2005 a 2007, uma grande concentração de trabalhos com ênfase nas abordagens "empirista-positivista hipotéticodedutiva" e "empirista-positivista", representando, respectivamente, 20\% e 63\% dos trabalhos analisados. Em ambas as abordagens, nota-se a predominância da preocupação em explicar a relação entre variáveis de um determinado fenômeno, levando-se em consideração um retrato da situação atual. A diferença entre as abordagens se dá pelo fato de que, nas dissertações classificadas como utilizando um enfoque hipotético-dedutivo, mostra-se, de forma explícita, que a pesquisa se embasa numa teoria, buscando confrontá-la com a realidade.

Segundo Bachelard (1985 apud LOPES, 1998, p.71), uma das principais características da concepção empírico-positivista é não colocar em crise a razão, não pôr em risco o método, manter o recurso monótono às certezas da memória. Talvez por isso, a abordagem empíricopositivista, como base, esteja predominando nas pesquisas realizadas nos últimos três anos no Programa de Pós-Graduação analisado. A Figura 1 apresenta, a seguir, a representação gráfica dos quantitativos dos trabalhos analisados separados por ano, segundo cada abordagem epistemológica.

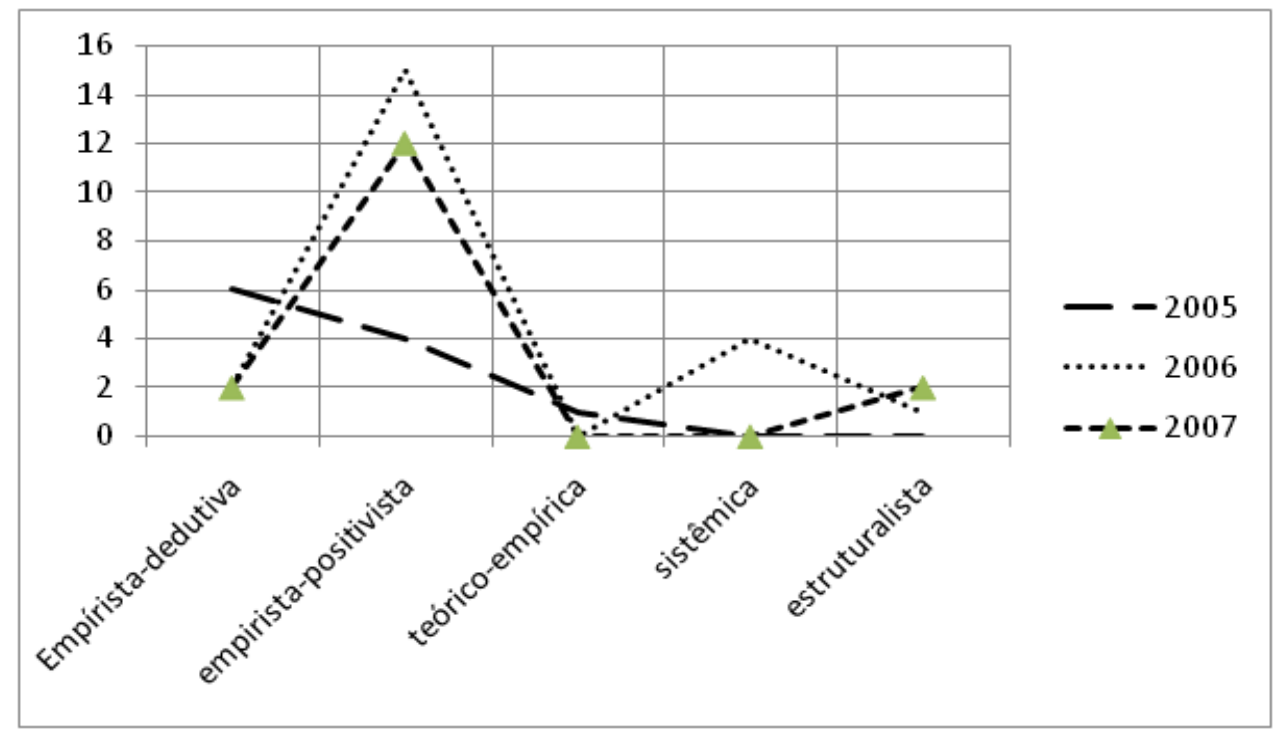

Figura 1 - Dissertações, por ano, segundo cada abordagem

O predomínio da abordagem positivista foi constatado em vários estudos e avaliações já realizados em outros programas. Segundo Farias (2004, p.3), "o paradigma positivista parece preponderar nas produções acadêmicas em administração". Sampaio e Perin (2006, p.193), parafraseando Kovacs et al. (2004), sustentaram que a orientação predominante nos trabalhos apresentados no ENANPAD, na área de marketing, é fortemente alinhada à tradição positivista, mostrando, assim, a sua influência dentro da administração.

Uma possível sugestão foi dada por Cerchiaro, Sauerbronn e Ayrosa (2004), para os quais, os pesquisadores da área têm-se dedicado a conceitualizar e apresentar seus resultados em base estritamente positivistas, temendo certamente a reprovação por parte de seus pares e a 
prostração acadêmica. Assim, percebe-se uma visão positivista ainda predominando na área de administração, inclusive, nos programas de pós-graduação. Por isso, visando obter uma melhor aceitação e aprovação por parte dos avaliadores, e não arriscando em confrontar a barreira dominante, favorável ao positivismo, busca-se seguir a tendência da maioria, seguindo o sistema filosófico dominante na área.

Nesse contexto, observou-se maior incidência de pesquisas descritivas, a preocupação com o aprofundamento e registro de teorias de base nos estudos, a atenção quanto à apresentação dos objetivos dos estudos e seus procedimentos metodológicos, bem como o abalizamento de recomendações de pesquisas.

A concentração nessas duas abordagens pode estar relacionada com a filosofia utilizada pelos orientadores do programa, como também, em função da dificuldade vivida pelos alunos que ingressam em programas de mestrado de definirem a sua problemática de estudo. Assim, a escolha do tema não seria em função de sua relevância e da discussão teórica desenvolvida, mas em função da possibilidade de aplicação dos métodos empíricos preconizados.

Por outro lado, os pesquisadores brasileiros têm buscado, incessantemente, melhorar a posição do país nas estatísticas internacionais de pesquisas científicas, tendo em vista a pressão que o Ministério da Educação, principalmente através da Coordenação de Aperfeiçoamento de Pessoal de Nível Superior (Capes), tem promovido numa tentativa de igualar o Brasil aos países desenvolvidos, em relação ao quantitativo de produção científica. Para isso, observa-se a tendência de sofrer fortes influências advindas dos Estados Unidos, principalmente ao observar que boa parte da literatura utilizada nas produções dessa área, aqui no Brasil, é de autores americanos (BERTERO; CALDAS; WOOD JR., 1999). Conforme Lima (1999, p.10), "há o reconhecimento da falta de citações de autores nacionais no conjunto da produção científica".

A pesquisa científica brasileira ocupava o 13 lugar, segundo indicou o então ministro da Educação Fernando Haddad (CAPES, 2009). Já em termos qualitativos, o desempenho do Brasil é mais tímido, sendo o $20^{\circ}$ colocado no mundo, onde o ranking mede o impacto dos trabalhos publicados, tendo como base o quanto eles são citados por outros trabalhos. Como há preocupação em melhorar a posição nacional, várias pesquisas são produzidas usando como citações, autores americanos, ficando desta forma, difícil construir produções que não sigam a tendência dos pesquisadores daquele país, reproduzindo as oscilações e os modismos norteamericanos (BERTERO; CALDAS; WOOD JR., 1999).

Esse modismo de inspiração nos Estados Unidos é destacado por Farias (2004, p.3) quando afirma que:

o primeiro passo para publicar no Brasil é ter um artigo, bem escrito, com uma temática atual, utilizando muita referência bibliográfica internacional, provavelmente replicar uma escola americana, um estudo realizado nos Estados Unidos, o que ajuda muito na sua publicação. 
Analisando esta mesma situação das pesquisas brasileiras ainda não terem uma personalidade própria, Bertero, Caldas e Wood Jr. (1999) ressaltam que a produção brasileira em administração é de qualidade duvidosa e pouco original, sofrendo fortes influências. Se ela não possui uma personalidade própria, como se pretende conquistar um espaço em nível mundial, quando se trata de pesquisas científicas? Por outro lado, outras áreas de pesquisas têm conquistado, lentamente, seus espaços no meio acadêmico internacional, com pesquisas de bastante repercussão, sendo publicadas em revistas de renome internacional. Mas no caso da administração, ainda persistem certas dificuldades para se expandir no sentido de conquistar também o seu espaço, assim como outras áreas do conhecimento (BERTERO; CALDAS; WOOD JR., 1999).

Bertero, Caldas e Wood Jr. (1999) também consideram que parte da nossa produção acadêmica, adota como referências obras de autores americanos de foco gerencialista e qualidade duvidosa, mais próprios de livrarias de aeroportos que de bibliotecas universitárias, mostrando assim, que não existe um melhor critério ao utilizar essas citações, e sim, apenas em citar, achando que com isso, o trabalho será melhor aceito pela comunidade acadêmica.

Fundamentando-se no que foi constatado, faz-se necessário, também, destacar que, a relevância e escolha dos problemas pesquisados, geralmente, são concebidas porque se interpreta essa relevância com base na maior proximidade dos problemas com o cotidiano do pesquisador. Por outro lado, na maioria das vezes, procura-se a necessidade de pesquisar problemas não tão complexos a fim de, através deles, obter os conhecimentos e práticas necessárias para a qualificação, como pesquisador, no tempo hábil estipulado pelo programa.

Entretanto, nota-se uma tendência, ainda em fase de crescimento no Brasil, da utilização de pesquisas qualitativas, incentivando a constituição ou o fortalecimento de uma abordagem de investigação que seja menos ingênua (D'ANGELO apud SAMPAIO; PERIN, 2006, p.196) no sentido de não se deixar condicionar por tendências adotadas por pesquisadores em outras nações, construindo, assim, a sua própria identidade científica. Mas para isso, o país necessita conquistar um espaço nesse meio, fato este que já está sendo efetuado gradativamente. Mas, nessa busca, é necessário ter o cuidado de, na ânsia de conquistar espaço com quantidade de produções, não perder a qualidade.

\section{CONSIDERAÇÕES FINAIS}

Portanto, de acordo com o que foi analisado nas dissertações, o objetivo da pesquisa foi logrado a partir da possibilidade de responder ao questionamento inicial proposto como pergunta de partida, sobre quais seriam as abordagens epistemológicas mais presentes nas dissertações produzidas, no Programa de Pós-Graduação analisado, no período de 2005 a 2007. 
No geral, o enfoque epistemológico mais presente foi o positivista, o qual está inserido nas duas abordagens com maior presença: empírico-positivista e empírico-positivista hipotético dedutiva.

Foi possível apurar, também, a frequência com que estudos nesses formatos têm sido realizados em outros programas em Administração de outras instituições por vários motivos, ficando a sensação de que, mesmo que a consciência de não ser possível equiparar ciências sociais com ciências exatas, em termos metodológicos, esteja "borbulhando" nas mentes dos pesquisadores sociais, a dificuldade de expurgar uma necessidade de constatação empírica de relação de causa e efeito é tamanha. Apesar disso, o estudo não pretendeu explicar o porquê dessa predominância positivista nos trabalhos produzidos no período analisado e, sim, apenas descrever tal fato. Porém, como colocado na análise dos resultados, é possível traçar algum direcionamento das causas para esse efeito. Não que sejam as únicas, mas já é um caminho.

Por fim, como resultado deste, espera-se contribuir com a obtenção e caracterização do perfil da pesquisa no campo da Administração, na medida em que forem explicitados os fundamentos epistemológicos utilizados na construção do conhecimento científico nesta área. Atenta-se à importância deste estudo, pela tentativa de mostrar as lacunas existentes na área do conhecimento em Administração, pois essa atitude poderá levar a novas pesquisas, analisando outros períodos e outras instituições ou mesmo pesquisas que possam explicar algumas das causas dessa predominância ainda permanente nos estudos em Administração, buscando também construir novas conceituações teóricas, revisões epistemológicas, destruição de mitos e elaboração de novas metodologias.

\section{REFERÊNCIAS}

1. AKTOUF, O. Administração e teorias das organizações contemporâneas: rumo a um humanismo-radical crítico? Organizações \& Sociedade, Salvador, v.8, n.21, p.13-33, mai./ ago., 2001.

2. BERTERO, C. O. O ensino de metodologia de pesquisa em administração. Revista de Administração de Empresas, Rio de Janeiro, v. 24, n. 4, out/dez, 1984.

3. BERTERO, C. O.; KEINERT, T. M. M. A evolução da análise organizacional no Brasil. Revista de Administração de Empresas, São Paulo, v. 34, n. 3, p.81-90, 1994.

4. BERTERO, C. O.; CALDAS, M. P.; WOOD JR., T. Produção científica em administração de empresas: provocações, insinuações e contribuições para um debate local. Revista de Administração Contemporânea, Rio de Janeiro, v.3, n.1, jan/abr, p.147-178, 1999.

5. BeRTERO, C. O. Prefácio. In: MOTTA, P. R. M.; PIMENTA, R. C.; RODRIGUES, E. M. T. Novas idéias em administração. Rio de Janeiro: FGV, 2006.

6. BRABO, L. Filosofia sistemática. 2007. Disponível em: <www.filosofia.catolico.org.br>. Acesso em: $18 / 07 / 2008$.

7. BUNGE, M. Epistemologia: curso de atualização. São Paulo: T. A. Queiroz e Edusp, 1980.

8. CERVO, A. L.; BERVIAN, P. A. Metodologia científica. São Paulo: McGraw-Hill, 1983. 
9. CERCHIARO, I. B.; SAUERBRONN, J. F. R.; AYROSA, E. A. T. Uma visão alternativa da pesquisa em marketing: como a fenomenologia pode contribuir para gerar conhecimento de marketing. In: ENCONTRO DE MARKETING DA ANPAD, 2004, Porto Alegre, Anais... Porto Alegre: ANPAD, 2004.

10. CHAUI, M. Convite à filosofia. São Paulo: Editora Ática, 2002.

11. Coordenação de Aperfeiçoamento de Pessoal de Nível Superior (CAPES). Produção Científica: ministro prevê inclusão do Brasil entre os dez maiores do planeta. Brasília, 06 mai 2009. Disponível em:< http://www.capes.gov.br/servicos/sala-de-imprensa/36-noticias/2654ministro-preve-inclusao-do-brasil-entre-os-dez-maiores-do-planeta->. Acesso em: 22/03/2010.

12. DEMO, P. Metodologia científica em ciências sociais. São Paulo: Atlas, 1981.

13. FARIAS, S. A. Em busca da inovação no marketing brasileiro: discutindo o processo de publicação de artigos em revista e congressos. In: ENCONTRO DE MARKETING DA ANPAD, 2004, Porto Alegre, Anais... Porto Alegre: ANPAD, 2004.

14. FAZENDA, I. C. A. Apresentando a força da alegria. In: FAZENDA, I. C. A. (Org.). A virtude da força nas práticas interdisciplinares. Campinas: Papirus, 1999.

15. FILHO, J. F. R. et al. Uma Análise das Abordagens Epistemológicas e Metodológicas da Pesquisa Contábil do Programa do Mestrado Multiinstitucional em Ciências Contábeis. In: ENANPAD, 30., 2006, Salvador. Anais... Salvador: ANPAD, 2006.

16. GAMBOA, S. S. Epistemologia da pesquisa em educação: estruturas lógicas e tendências metodológicas. 1987. Tese de Doutorado em Educação. Universidade Estadual de Campinas: Campinas, 1987.

17. GARCIA, F. C.; CARRIERI, A. P. Nota técnica: Dados em estudos organizacionais Representações simbólicas metamorfoseadas pelo pesquisador? In: CALDAS, M.; FACHIN, R.; FISCHER, T. (Orgs.). Handbook de estudos Organizacionais. v.2. São Paulo: Atlas, 2001.

18. GIL, A. C. Métodos e técnicas de pesquisa social. São Paulo: Atlas, 1987.

19. IUDÍCIBUS, S.; THEÓPHILO, C. R. As Novas Abordagens Metodológicas na Pesquisa em Contabilidade Gerencial. In: CONGRESO DEL INSTITUTO INTERNACIONAL DE COSTOS $Y \|$ CONGRESO DE LA ASOCIACIÓN ESPAÑOLA DE CONTABILIDAD DIRECTIVA, 2001, 7., León. Anais... León: VII CONGRESO DEL INSTITUTO INTERNACIONAL DE COSTOS Y II CONGRESO DE LA ASOCIACIÓN ESPAÑOLA DE CONTABILIDAD DIRECTIVA, 2001, p.1.

20. IVONE, G. A. S. Uma análise das abordagens epistemológicas e metodológicas da pesquisa contábil no Programa do Mestrado Multiinstitucional em Ciências Contábeis. 2005. Dissertação de Mestrado - Programa Multi-Institucional e Interregional de Pós-Graduação em Ciências Contábeis do convênio UNB, UFPB, UFPE e UFRN. UFPE: Recife, 2005.

21. KIRSHBAUM, C.; PORTO, E. C.; FERREIRA, F. C. M. Neo-institucionalismo na produção acadêmica em administração. Revista de Administração de Empresas, Rio de Janeiro, v.3, n. 1, art. 12, jan/jun, 2004.

22. LEAVITT, H. J. The old days, hot groups and managers' lib. Administrative Science Quarterly, v. 41, n. 2, p. 288-300, 1996. 
23. LIMA, J. B. Pesquisa qualitativa e qualidade na produção científica em administração de empresas. In: ENANPAD, 1999, Foz do Iguaçu, Anais... Foz do Iguaçu: ANPAD, 1999.

24. LOPES, A. R. C. História do currículo da pós-graduação em educação da UFRJ (1972-1981) concepções de conhecimento e pesquisa. Revista Brasileira de Educação, p.57-73, jan/abr, 1998.

25. MARSDEN, R.; TOWNLEY, B. A coruja de minerva: reflexões sobre a teoria na prática. In: CALDAS, M.; FACHIN, R.; FISCHER, T. (Orgs.). Handbook de estudos organizacionais. v.2. São Paulo: Atlas, 2001.

26. MARTINS, G. A. Epistemologia de pesquisa em administração. 1994. Tese de Livre Docência FEA/USP. São Paulo: USP, 1994.

27. MELLO, S. C. B.; DUTRA, H. F. O.; OLIVEIRA, P. A. S. Serviço educacional : a percepção de qualidade do aluno de administração da Universidade Federal de Pernambuco. Revista Produção, Florianópolis, v.10, p.1-9, jan/abr, 2000.

28. MOREIRA, M. A. O mestrado (profissional) em ensino. Revista Brasileira de Pós-Graduação, v.1, n.1, p. 131-141, julho, 2004.

29. PRATA, M. Uma tese é uma tese. O Estado de São Paulo, São Paulo, 7 out. 1998. Caderno 2.

30. QUIVY, R.; CAMPENHOUDT, L.V. Manual de investigação em ciências sociais. 3.ed. Lisboa: Gradiva, 2003.

31. REED, M. Teorização organizacional: um campo historicamente contestado. In: CALDAS, M.; FACHIN, R.; FISCHER, T. (Orgs.). Handbook de estudos organizacionais. v.1. São Paulo: Atlas, 2007.

32. RICHARDSON, R. J. Pesquisa sociais métodos e técnicas. São Paulo: Atlas, 1999.

33. SAMPAIO, C. H.; PERIN, M. G. Pesquisa científica da área de marketing: uma revisão histórica. Revista de Administração Contemporânea, Rio de Janeiro, v.10, n.2, abr/jun, p.179-202, 2006.

34. SCHRADER, A. Introdução à pesquisa social empírica: um guia para o planejamento, a execução e a avaliação de projetos de pesquisa não-experimentais. 2.ed. Porto Alegre: Globo, 1978.

35. STARKEY, K.; MADAN, P. Bridging the relevance gap: aligning stakeholders in the future of Management research. British Journal of Management, v. 12, special issue, p.3-26, 2001.

36. TRIVIÑOS, A. N. S. Introdução à pesquisa em ciências sociais: a pesquisa qualitativa em educação. São Paulo: Atlas, 2007.

37. VERGARA, S. C.; CARVALHO JR., D. S. Nacionalidade dos autores referenciados na literatura brasileira sobre organizações. Revista Brasileira de Administração Contemporânea, Rio de Janeiro, v. 1, n. 6, p. 169-188, 1995. 